\title{
Transplantation for Acute Liver Failure in Patients Exposed to NSAIDs or Paracetamol (Acetaminophen)
}

\author{
The Multinational Case-Population SALT Study
}

\author{
Sinem Ezgi Gulmez • Dominique Larrey • Georges-Philippe Pageaux • Severine Lignot • Régis Lassalle • \\ Jérémy Jové · Angelo Gatta • P. Aiden McCormick • Harold J. Metselaar • Estela Monteiro • \\ Douglas Thorburn • William Bernal • Irene Zouboulis-Vafiadis • Corinne de Vries • Susana Perez-Gutthann • \\ Miriam Sturkenboom • Jacques Bénichou • Jean-Louis Montastruc • Yves Horsmans • Francesco Salvo • \\ Fatima Hamoud - Sophie Micon • Cécile Droz-Perroteau • Patrick Blin • Nicholas Moore \\ Published online: 17 January 2013 \\ (c) The Author(s) 2013. This article is published with open access at Springerlink.com
}

\begin{abstract}
Background Most NSAIDs are thought to be able to cause hepatic injury and acute liver failure (ALF), but the event rates of those leading to transplantation (ALFT) remain uncertain.

Objectives The aim of the study was to estimate population event rates for NSAID-associated ALFT

Methods This was a case-population study of ALFT in 57 eligible liver transplant centres in seven countries (France, Greece, Ireland, Italy, The Netherlands, Portugal and the UK). Cases were all adults registered from 2005 to 2007
\end{abstract}

On behalf of the SALT Study Group.

See Online Resource 1 for a list of the SALT-1 study participants.

Electronic supplementary material The online version of this article (doi:10.1007/s40264-012-0013-7) contains supplementary material, which is available to authorized users.

S. E. Gulmez · S. Lignot · R. Lassalle · J. Jové · F. Salvo ·

F. Hamoud · S. Micon · C. Droz-Perroteau - P. Blin · N. Moore

University of Bordeaux Segalen, Bordeaux, France

S. E. Gulmez $(\bowtie) \cdot$ S. Lignot · R. Lassalle · J. Jové ·

F. Hamoud - S. Micon - C. Droz-Perroteau · P. Blin .

N. Moore $(\triangle)$

INSERM CIC-P0005 Pharmaco-épidémiologie, INSERM U657,

Service de Pharmacologie, Université Bordeaux Segalen,

Bâtiment Le Tondu, Case 41, 146, Rue Léo Saignat,

33076 Bordeaux Cedex, France

e-mail: sinemezgi.gulmez@u-bordeaux2.fr

N. Moore

e-mail: nicholas.moore@pharmaco.u-bordeaux2.fr

D. Larrey · G.-P. Pageaux

University of Montpellier, Montpellier, France

A. Gatta

Padua University Hospital, Padova, Italy for a liver transplant following ALFT without identified clinical aetiology, exposed to an NSAID or paracetamol (acetaminophen) within 30 days before the onset of clinical symptoms. NSAID and paracetamol population exposures were assessed using national sales data from Intercontinental Marketing Services (IMS). Risk was estimated as the rate of ALFT per million treatment-years (MTY).

Results In the 52 participating centres, 9479 patients were registered for transplantation, with 600 for ALFT, 301 of whom, without clinical aetiology, had been exposed to a drug within 30 days. Of these 301 patients, 40 had been exposed to an NSAID and 192 to paracetamol (81 of whom were without overdose).

Event rates per MTY were 1.59 (95\% CI 1.1-2.2) for all NSAIDs pooled, 2.3 (95\% CI 1.2-3.9) for ibuprofen, 1.9 (95\% CI 0.8-3.7) for nimesulide, 1.6 (95\% CI 0.6-3.4) for diclofenac and 1.6 (95\% CI 0.3-4.5) for ketoprofen.

P. A. McCormick

Liver Unit, St Vincent's University Hospital and University

College Dublin, Dublin, Ireland

H. J. Metselaar · M. Sturkenboom

Erasmus Medical Centre, Rotterdam, The Netherlands

E. Monteiro

University Hospital Santa Marie, Lisbon, Portugal

D. Thorburn

Royal Free Hospital, London, UK

W. Bernal

King's College Hospital NHS Foundation Trust, London, UK

I. Zouboulis-Vafiadis

Athens University School of Medicine, Athens, Greece 
For paracetamol, the event rate was 3.3 per MTY (95\% CI 2.6-4.1) without overdoses and 7.8 (95\% CI 6.8-9.0) including overdoses.

Conclusions ALF leading to registration for transplantation after exposure to an NSAID was rare, with no major difference between NSAID. Non-overdose paracetamolexposed liver failure was twice more common than NSAID-exposed liver failure.

\section{Background}

Acute liver injury is one of the more common reasons for withdrawal of drugs from the market, or for interruption of their development [1-3]. NSAIDs have often been involved in liver injury $[1,4]$, and adverse hepatic reactions have been reported for most NSAIDs [5]. However, general population studies have not found a clear difference between NSAIDs for hepatic reactions not leading to transplantation $[6,7]$. Because of clusters of spontaneous reports of suspected hepatotoxicity with nimesulide, the European Medicines Agency's (EMA) Committee on Human Medicinal Products (CHMP) required an epidemiological study of NSAID-exposed acute liver failures (ALF) leading to transplantation (ALFT).

The objective of the SALT (Study of Acute Liver Transplantation) study, conducted in seven European countries (France, Greece, Ireland, Italy, The Netherlands, Portugal and the UK), was therefore to assess the population rates of ALFT without identified clinical aetiology in patients exposed to NSAIDs.

\section{Patients and Methods}

The SALT study was a multicentre, multinational, casepopulation study [8] conducted in seven countries, and designed to provide estimates of the population rates of registration on transplantation lists for ALFT patients exposed to an NSAID or paracetamol (acetaminophen)

\author{
C. de Vries \\ University of Bath, Bath, UK \\ S. Perez-Gutthann \\ RTI Health Solutions, Barcelona, Spain \\ J. Bénichou \\ University of Rouen, Inserm U657, Rouen, France \\ J.-L. Montastruc \\ University of Toulouse, Toulouse, France \\ Y. Horsmans \\ University Cath Louvain, Brussels, Belgium
}

within 30 days before the onset of clinical symptoms of liver disease (index date).

The study protocol was approved by the CHMP, the data protections authorities in each of the seven countries, and by Ethics Committees and Research and Development (R\&D) committees as required [9]. The study period for inclusion in the liver transplant registries was 2005-2007, the 3-year period preceding the last nimesulide referral to regulatory authorities. Data were collected from January 2009 to October 2011.

\subsection{Centres and Cases}

All 62 liver transplantation centres in the seven countries were identified. Centres dealing exclusively with cancer (one centre) or children (four centres) were excluded. The 57 eligible centres were contacted for participation. In participating centres, all adults ( $\geq 18$ years of age) who were resident in the country and registered on the liver transplantation waiting lists during the 3-year study period were identified. National computerized registries were used in France, Ireland, The Netherlands and the UK for case identification, and centre registries were used for the three other countries. Anonymized information (sex, age, country resident, liver disease history and histopathology) was extracted for all patients and recorded from medical files by trained clinical research assistants, to separate chronic liver failure (CLF) from ALFT [10-12]. ALFT status was verified by the local transplant centre hepatologist, and validated by a national case classification hepatologist. For all ALFT cases, symptoms and dates, laboratory results, viral workups, autoantibodies, concomitant factors and diseases that could help to identify clinically relevant aetiologies, and drug exposure history were extracted from all available data and verified by the local hepatologist. Relevant documents were anonymized and scanned for further reference. Data were then reviewed and validated by the national case classification hepatologist, who also defined the date of onset of liver disease (index date) and classified patients as ALFT with or without an identified clinical aetiology. Typical identified clinical aetiologies were viral or autoimmune hepatitis, mushroom toxicity, vascular causes and other, as described in the medical charts. Cases with clinically defined aetiologies were not further explored for drug exposure.

In cases without clinically defined aetiologies, drug exposure, including herbals and homoeopathic medicines, was ascertained from the patient's medical files, including plasma drug concentrations if available. The timing of drug ingestion or exposure was compared with the index date, to qualify the exposure as started after the index date (drug excluded), or taken before the index date, within $7,15,30$ or 90 days, according to international causality consensus conference criteria [13-16]. Cases without clinically 


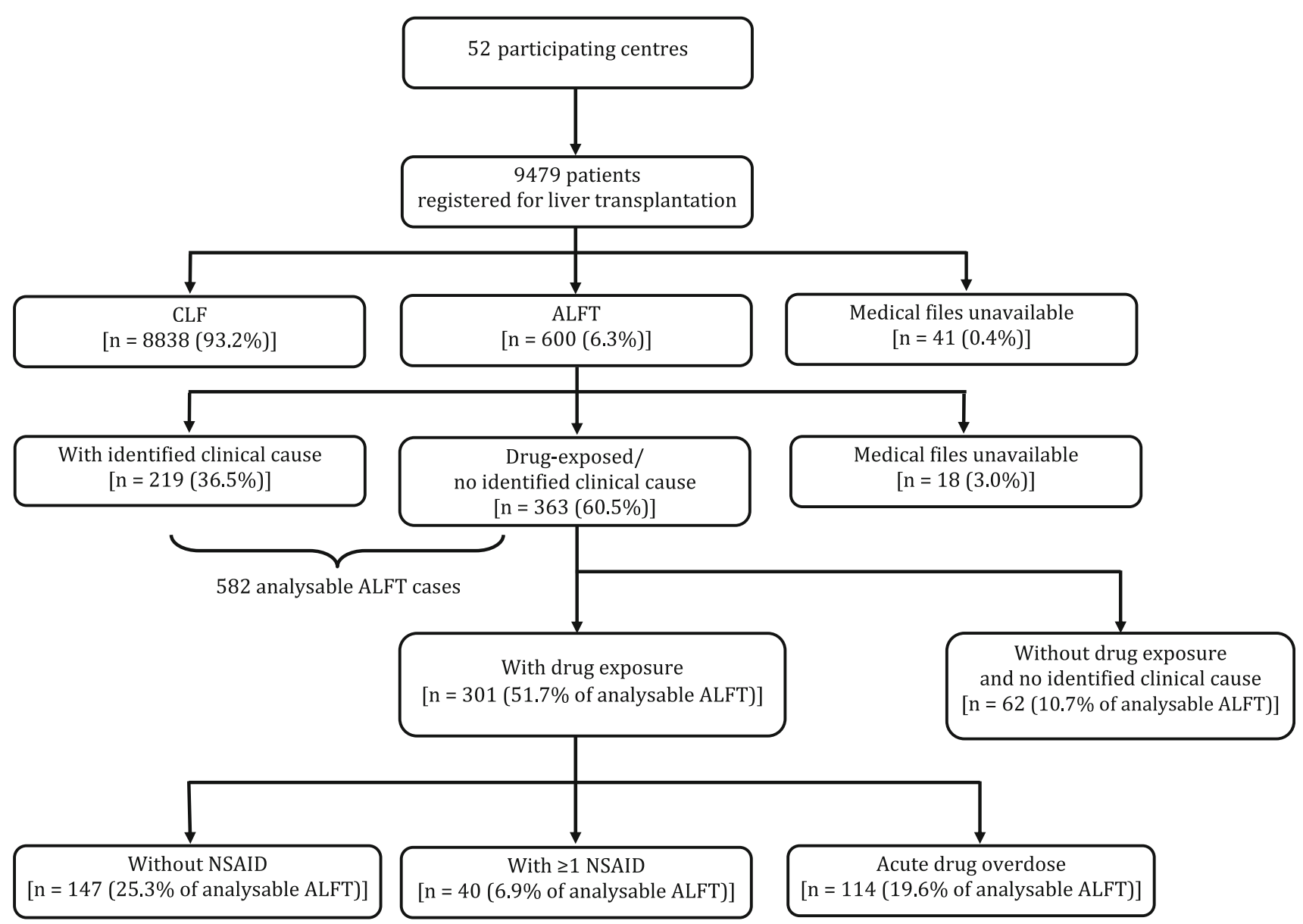

Fig. 1 Patient disposition in the SALT study. Drug exposure (NSAID or other) was considered within 30 days before date of first clinical symptoms. ALFT acute liver failure leading to transplantation, $C L F$ chronic liver failure

defined aetiology were then classified into (i) not exposed to drugs within 30 days before the index date; (ii) exposed to any drug within 30 days before the index date, without drug overdose; and (iii) acute drug overdose, with or without suicidal intent, with demonstrated high plasma drug concentrations or documented and quantified overdose. Other exposure-time windows (90, 15 and 7 days before the index date) were used for sensitivity analyses.

Paracetamol overdoses were confirmed by the case adjudication committee, based on case description of documented overdosing (number of tablets reported taken, empty packs found with the patient, patient or family report of voluntary overdose, etc.) and/or toxic plasma paracetamol concentrations found. All other cases where paracetamol use was identified within 30 days before the index date were considered as non-overdose.

\subsection{Population Exposure}

Intercontinental Medical Services Ltd (IMS; London, UK) provided per-country population exposure to NSAIDs and paracetamol. These data do not include point-of-sale general outlet data for the UK, Ireland and The Netherlands. Population exposure was described as the number of units and number of defined daily doses (DDD) [17] sold in each country over the 3-year period, and as treatment-years determined from the observed average daily dose as reported by prescription panels. Purely paediatric formulations were excluded and parenteral preparations were included. The IMS data were adjusted to the contribution of non-participating centres to overall transplantation activity in each country, as determined from the transplantation registries. Fixed-dose associations of NSAIDs (e.g. diclofenac + misoprostol) or paracetamol (e.g. paracetamol + codeine) were attributed to the main component of interest (NSAID or paracetamol). When paracetamol was associated with an NSAID (e.g. fixed-dose paracetamol + ibuprofen), the cases and sales were attributed to both drugs.

Event rates are reported as the number of cases per billion DDD, and as the number of cases per million patient-years of treatment, with exact $95 \%$ Poisson confidence intervals $(95 \% \mathrm{CI})$.

All statistical analyses were performed using SAS software (SAS Institute, NC, USA), version 9.1. 
Table 1 Demographic characteristics of patients registered to transplantation waiting lists for acute liver failure exposed to drugs within 30 days of index date, in seven European countries (2005-2007)

\begin{tabular}{|c|c|c|c|c|}
\hline Patient characteristics & $\begin{array}{l}\text { With } \geq 1 \text { NSAID } \\
(n=40)\end{array}$ & $\begin{array}{l}\text { Without NSAID } \\
(n=147)\end{array}$ & $\begin{array}{l}\text { Acute drug } \\
\text { overdose }(n=114)\end{array}$ & $\begin{array}{l}\text { Total } \\
(n=301)\end{array}$ \\
\hline Male $[\mathrm{n}(\%)]$ & $11(27.5)$ & $48(32.7)$ & $44(38.6)$ & $103(34.2)$ \\
\hline Mean age at registration on transplant list [years (SD)] & $43.9(14.6)$ & $39.1(12.5)$ & $33.6(10.9)$ & $37.7(12.7)$ \\
\hline Transplanted [n (\%)] & $34(85.0)$ & $127(86.4)$ & $83(72.8)$ & $244(81.1)$ \\
\hline Exposed to NSAID $\leq 30$ days before index date [n (\%)] & $40(100.0)$ & $0(0.0)$ & $11(9.6)$ & $51(16.9)$ \\
\hline $\begin{array}{l}\text { Exposed to paracetamol (acetaminophen) or paracetamol } \\
\text { combinations } \leq 30 \text { days before index date [n }(\%)]\end{array}$ & $22(55.0)$ & $59(40.1)$ & $111(97.4)$ & $192(63.8)$ \\
\hline $\begin{array}{l}\text { Exposed to drugs other than NSAIDs } \leq 30 \text { days } \\
\text { before index date }[\mathrm{n}(\%)]\end{array}$ & $35(87.5)$ & $147(100.0)$ & $114(100.0)$ & $296(98.3)$ \\
\hline
\end{tabular}

\section{Results}

\subsection{Participating Centres}

Of 57 eligible centres, 54 (94.7\%) agreed to participate: 20/21 in France, 19/20 in Italy, 2/2 in Greece, 3/3 in The Netherlands, $2 / 3$ in Portugal, $1 / 1$ in Ireland and 7/7 in the UK. No specific reason was given for non-participation, other than excess workload. One centre in the UK and one in Italy that had initially accepted to participate could not provide data within the study timeframe [9].

\subsection{Acute Liver Failure Cases}

In the 52 contributing centres (91.2\%), 9479 patients on liver transplantation waiting lists were identified (Fig. 1), representing over $90 \%$ of such patients in these countries. Medical files were not available for 41 patients $(0.4 \%)$, 8838 patients (93.2 \%) were listed for CLF and 600 (6.3\%) for ALFT. Among the ALFT patients, the medical files were missing or incomplete for 18 patients $(3.0 \%)$ and case characteristics could not be ascertained for these 18 patients. In 219 cases (36.5\%), ALFT was explained by a defined clinical aetiology. These cases were not further explored for drug exposure. These clinical aetiologies were viral hepatitis B $(34.7 \%)$, autoimmune hepatitis (18.3\%), other viruses $(7.3 \%)$, mushroom toxicity $(6.0 \%)$, Wilson's disease $(5.5 \%)$, arterial thrombosis or Budd-Chiari syndrome $(6.8 \%)$ and various other causes (e.g. acute alcoholic or post-traumatic). Clinical aetiologies were not found in 363 cases, which were considered as clinically unexplained. Overall, 187 non-overdose cases had been exposed to at least one drug within 30 days before the index date: 40 to at least one NSAID and 147 to drugs other than NSAIDs. Two-thirds were female, mean age was around 40 years and over $81 \%$ were eventually transplanted (Table 1). ALFT was attributed to overdose in 114 cases. In 62 cases no drug exposure was found within 30 days before the index date.

\subsection{NSAID- and Paracetamol-Exposed Cases}

Overall, 40 cases had been exposed to a total of 43 NSAIDs within 30 days before the index date. One case had been exposed only to topical diclofenac (Table 2). Thirty-five had also been exposed to other drugs, including paracetamol in 22 cases (55.0 \%; Table 1). Of the 147 non-NSAID and non-overdose cases, another 59 (40.1\%) had been exposed to non-overdose paracetamol within 30 days before the index date.

Overall, $111(97.4 \%)$ of the 114 overdoses were attributed to paracetamol.

\subsection{Event Rates}

The overall NSAID event rate was $1.59(95 \%$ CI 1.14-2.17) ALFT cases per million treatment-years

Table 2 Number of patients with acute liver failure leading to transplantation exposed to various NSAIDs as a function of time before first symptoms

\begin{tabular}{lcccc}
\hline NSAID & $\begin{array}{l}90 \text { days } \\
(n=44 \\
\text { cases })\end{array}$ & $\begin{array}{l}30 \text { days } \\
(n=40 \\
\text { cases })\end{array}$ & $\begin{array}{l}15 \text { days } \\
(n=37 \\
\text { cases })\end{array}$ & $\begin{array}{l}7 \text { days } \\
(n=34 \\
\text { cases })\end{array}$ \\
\hline Celecoxib & 2 & 2 & 2 & 1 \\
Diclofenac $^{\mathrm{a}}$ & 7 & 6 & 5 & 5 \\
Etodolac & 2 & 2 & 2 & 2 \\
Ibuprofen & 14 & 13 & 11 & 11 \\
Indometacin & 1 & 1 & 1 & 1 \\
Ketoprofen & 3 & 3 & 3 & 3 \\
Ketorolac & 2 & 2 & 2 & 1 \\
Meloxicam & 1 & 0 & 0 & 0 \\
Naproxen & 2 & 2 & 2 & 2 \\
Niflumic acid & 1 & 1 & 1 & 1 \\
Nimesulide & 9 & 8 & 7 & 6 \\
NSAID unspecified & 3 & 3 & 3 & 2 \\
All exposures & 47 & 43 & 39 & 35
\end{tabular}

${ }^{a}$ One case with diclofenac in topical form 
(MTY), corresponding to 4.37 cases per billion DDD, with no significant difference between individual NSAID (Fig. 2). The common NSAIDs celecoxib, diclofenac, ibuprofen, ketoprofen, naproxen and nimesulide all had point estimates below 10 per MTY or per billion DDD, and an upper limit of the $95 \%$ CI below 5 per MTY, except for naproxen (5.89) and celecoxib (7.79). Event rates for all NSAIDs pooled were almost four times higher in Ireland than in all countries pooled (Table 3 ).

Over the same period, 192 cases had been exposed to paracetamol within 30 days before the index date, 81 of which were without overdose, resulting in ALFT rates of 3.31 (95\% CI 2.63-4.11) per MTY for non-overdose paracetamol and 7.84 (95\% CI 6.77-9.04) per MTY when overdoses were included (Fig. 2). CIs did not overlap with those of event rates for all NSAIDs pooled.

These results remained consistent over the sensitivity analyses, such as increasing the exposure window to 90 days or reducing it to 15 or 7 days, removing NSAIDexposed cases also exposed to paracetamol or including cases with paracetamol overdose that had also been exposed to NSAIDs (data not shown).

Among the 147 ALFT cases not exposed to an NSAID, the most commonly found drug was paracetamol (40.1\%), followed by psycholeptics (Anatomical Therapeutic Chemical [ATC] class N05; $15.6 \%$ ) and antidepressants
(ATC code N06A; $7.5 \%$ ). Cannabis was found in ten cases $(6.8 \%)$ and herbals found in seven cases $(4.8 \%)$. Other drugs mentioned include rifampicin (rifampin) and/or other antituberculosis agents, amoxicillin or omeprazole.

\section{Discussion}

This case-population study of liver transplant in over 227 million inhabitants could not demonstrate clearly different severe liver toxicity between the mainstream NSAIDs, and the upper limits of the $95 \%$ CIs, which indicate the greatest risk that one could confidently exclude, were similar. These results reproduce and confirm the results of population studies of less severe hepatic reactions $[6,7]$. This study was not designed to look at ALF not listed for transplantation.

The main strength of the study is that all cases of ALF listed for transplantation are registered on transplantation lists, whether the transplant was actually done or not. Percountry identification of cases can therefore be complete. This is a prerequisite for a case-population approach [8], and allows a measure of absolute risk. Participating centres represented over $90 \%$ of all liver transplant units in the countries considered. The number of potential cases in nonparticipating centres was known from national or local registries, which allowed the adjustment of exposure data.

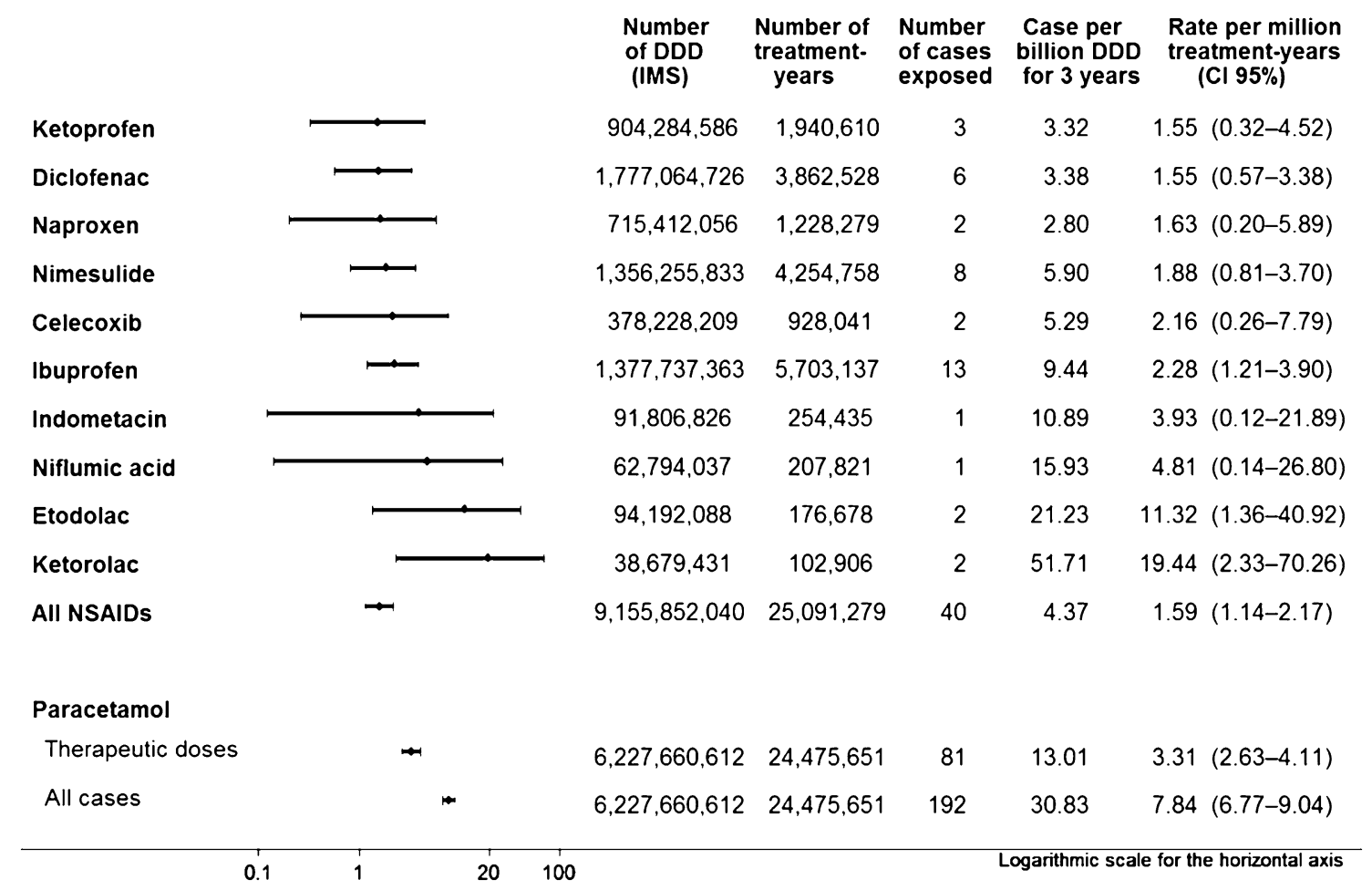

Fig. 2 Forest plot and event rates for exposure to an NSAID or paracetamol (acetaminophen) [non-overdose only, or all cases including intentional and non-intentional overdose] within 30 days before the date of the first clinical symptoms. $D D D$ defined daily doses, IMS Intercontinental Medical Services Ltd 
Table 3 Per-country incidence rates of acute liver failure leading to transplantation exposed to any NSAID within 30 days before index date in seven European countries (2005-2007). Exposure is adjusted for centre participation

\begin{tabular}{lccccc}
\hline Countries & $\begin{array}{l}\text { Number of } \\
\text { DDD (IMS) }\end{array}$ & $\begin{array}{l}\text { Number of } \\
\text { treatment-years }\end{array}$ & $\begin{array}{l}\text { Number of cases } \\
\text { exposed to an NSAID }\end{array}$ & $\begin{array}{l}\text { Cases per billion } \\
\text { DDD over 3 years }\end{array}$ & $\begin{array}{l}\text { Rate per million } \\
\text { treatment-years (95 \% CI) }\end{array}$ \\
\hline France & $2,526,930,718$ & $6,644,920$ & 9 & 3.56 & $1.35(0.62-2.57)$ \\
Greece & $591,913,320$ & $1,492,625$ & 0 & 0 & $0.00(0.00-2.47)$ \\
Ireland & $186,340,332$ & 488,393 & 3 & 16.1 & $6.14(1.27-17.96)$ \\
Italy & $2,763,378,262$ & $8,942,220$ & 10 & 3.62 & $1.12(0.54-2.06)$ \\
Portugal & $532,195,161$ & $1,382,853$ & 0 & 0 & $0.00(0.00-2.67)$ \\
Netherlands & $473,274,972$ & 928,021 & 4 & 8.45 & $4.31(1.17-11.03)$ \\
UK & $2,081,819,276$ & $5,212,248$ & 14 & 6.72 & $2.69(1.47-4.51)$ \\
Total & $9,155,852,040$ & $25,091,279$ & 40 & 4.37 & $1.59(1.14-2.17)$ \\
\hline
\end{tabular}

$D D D$ defined daily doses, IMS Intercontinental Medical Services Ltd

Transplantations are performed only in selected and accredited centres, with expert hepatologists who are very cognizant of liver failure. We are therefore confident not to have missed any of our target cases (ALF leading to registration for transplantation) and to have the best information available on causes and exposures.

This was a study of only ALF cases that led to registration for transplantation, not of all ALF. Cases not registered for transplantation might correspond to patients older than the age limit of transplantation, which is a potential limitation of our study, or patients who die before they can be listed for transplantation or who are not considered for transplantation for other reasons. If the reason for not transplanting is not related to exposure to the drugs of interest, missing these cases that might have been registered for transplantation but that were not transplanted would decrease the overall study power, but would not bias the results. Since the drugs were all in the same therapeutic class, it is unlikely that differential exposure to any individual drug would be a reason to decide to transplant or not to transplant a patient. The multi-country nature of the study can also compensate for any country-specific drugrelated bias.

Other studies have included patients with less-severe ALF and found similar results to ours [6,7]. Because lesssevere hepatic injuries might be hospitalized in many different settings, there is no possibility of the exhaustive countrywide retrieval of cases that are necessary for the case-population design used here.

Under-ascertainment of actual drug exposure in patients, related to poor history taking in transplant centres, might spuriously decrease the numerator. The medical history of liver transplant patients is usually thoroughly explored before transplantation, including information from general practitioners (GPs) and other sources. For confidentiality reasons, we could not seek further information from GPs or patients; however, from our expert board it is unlikely that relevant information from the GP would be missing from the hospital files. Nevertheless, patients may have had exposures or diseases unknown to the GP [18-20]. This might be especially true for over-the-counter (OTC) drugs such as paracetamol or ibuprofen. This could artificially reduce the event rates for these drugs, but would not change the findings of the study concerning prescription NSAIDs.

Facing an otherwise unexplained ALF, clinicians might tend to look for evidence of exposure to 'known' hepatotoxic drugs such as nimesulide, diclofenac or paracetamol more than exposure to other drugs, including other NSAIDs. These may then be under-ascertained and bias the result in disfavour of known hepatotoxic drugs (notoriety bias). On the other hand, because adverse hepatic reactions have been reported for many NSAIDs [5], there is little reason that any one would have been reported more or less often than others. For paracetamol, the uncertainty lies between underreporting of OTC paracetamol and the search for hepatotoxic drugs. Underreporting of OTC use would reduce the apparent risk of paracetamol, which in this study would be a conservative bias and could not explain the 2-fold higher event association with paracetamol.

The choice of the 30-day exposure window was based on causality assessment methods from consensus conferences [13-15], which state that it would be very unlikely that a drug stopped more than 30 days before the onset of first symptoms might be associated with acute hepatotoxicity, especially since NSAIDs such as ibuprofen, diclofenac or nimesulide have half-lives ranging from 2 to 8 hours.

Treatment duration was very rarely recorded, even for those patients who were still on the medication at the time of symptom onset, so we cannot describe a duration-oftreatment effect. Considering the small number of cases with individual drugs, it might have been unwise to attempt any kind of systematic case description. This should probably come from studies of less severe but more frequent cases. This assumes that the different NSAIDs included in the analysis were expected to be used in 
subpopulations with similar risk factors of developing ALF. Ibuprofen might be used in younger patients for a shorter duration of time [21], which could contribute to a lower event rate. The other NSAIDs are used in mostly similar populations in countries where this information exists [21, 22].

Because we did not have access to the actual number of users in each country, we chose to use overall population exposure measures, in DDD or treatment-years. The same data source (IMS) was used for all countries and all NSAIDs or paracetamol. This includes all sales to pharmacies, including OTC resale, but not sales in supermarkets, convenience stores or petrol stations, which are possible in the UK, Ireland or The Netherlands. These artificially lower exposures and may result in higher apparent event rates in these countries for drugs sold in such outlets, mostly ibuprofen and paracetamol. This would not affect drugs that are prescription-only in the countries considered, such as diclofenac, ketoprofen or nimesulide. In France, OTC ibuprofen and paracetamol are sold only in pharmacies, so that the sales data for these are complete.

Sales data were adjusted for the non-contributing transplantation centres. Since the same source was used for all drugs in all countries, any distortion would affect all drugs in the same manner, preserving the internal validity of the results. Expressing the results per DDD based on theoretical daily treatment as used for drug statistics, or as patient-years based on average prescribed dose, does not materially change the results. In this study we did not have access to the absolute number of patients treated with individual drugs, only quantities converted to DDD. This unit provides a standardized way to measure per country or per capita drug use that can be compared across and between drugs and drug families. Treatment-years are calculated from the average daily dose observed in patient panels in each country, making them perhaps a better metric because they take into account different drug prescription patterns between countries and drugs. If all drugs are used in more or less the same way, then the treatment-years are directly related to the number of patients and average prescription, and treatment-years might be an appropriate proxy for the number of users. These crude measures have the advantage of simplicity and robustness, but the inconvenience of being rather insensitive.

Event rates for NSAIDs were less than ten cases per million patient-years of treatment or billion DDD sold over 3 years, all NSAIDs combined or for individual drugs, consistent with other data for fulminant hepatitis [23]. This makes any attempt to measure more precisely possible differences among individual NSAIDs very difficult. Considering the small number of cases, and the very nonspecific nature of liver pathology at the advanced stage of liver failure in these patients, it was not possible to identify specific pathological features, risk factors for one or other of the NSAIDs, or elements suggesting mechanisms of severe liver injury. From other studies, no specific mechanism of toxicity has been identified for individual NSAIDs other than diclofenac and sulindac [24-27]. Nevertheless, these two drugs did not seem to be associated with excess risk of hepatotoxicity in the present study. In other registries of drug-induced liver injury (DILI), antibiotics seem to be more often associated with DILI than NSAIDs. This might be related to the recording of less severe toxicity or cholestatic liver disease not leading to transplantation, which would not appear in our study. It might also be related to real differences in drug toxicity between countries, for unidentified reasons.

We found a 2- to 3-fold higher event rate for nonoverdose paracetamol compared with all NSAIDs pooled, based on the same criteria used for NSAIDs. This has not been generally described, paracetamol toxicity being reported as essentially associated with overdose. There may be several reasons for this: OTC paracetamol is usually not recorded in claims databases or in medical databases; and in field studies there may be underascertainment or dismissal of non-overdose paracetamol exposure. The hepatotoxicity of paracetamol has been generally thought to be confined to overdose [3, 28, 29], including staggered overdoses [30], although there have been studies showing an association of paracetamol at therapeutic doses and liver injury $[3,31,32]$ in addition to case reports [33]. Others dispute this association [34-36].

We found paracetamol in $40 \%$ of the cases of ALFT where any drug was found during the 30 days before the first symptoms (more often than any other drug). When this is compared with population exposure, in DDD or treatment-years, the event rates were 2- to 3-fold greater than with NSAIDs. This may be purely coincidental, and in most cases there may be another explanation [35], but nonoverdose paracetamol might also play a direct or indirect causal role [31, 33], maybe through depletion of glutathione, reducing liver detoxification capabilities [37, 38]. Because paracetamol may be bought OTC in supermarkets and petrol stations (albeit in very small quantities), and this would not be captured in the UK, Ireland or The Netherlands, there could be concern about overestimation of the event rate for paracetamol. However, considering the event rate differential with all NSAIDS, the fraction thus missed would have to be half of the overall sales of all seven countries to explain the difference in event rates between paracetamol and all NSAIDs pooled. Such a hypothesis would appear to be somewhat far-fetched, especially since in other countries all sales are captured.

Because patients in pain require medication to alleviate the pain, the choice is not really between NSAID and no medication, but between one analgesic and another. In this 
case, avoiding any one of the mainstream NSAIDs because of excess reporting of liver toxicity would shift the use and risk to another NSAID. This would probably not change the individual per-patient risk of severe hepatic failure, which is essentially the same for the mainstream NSAIDs. Shifting to paracetamol might actually double the risk of ALF, even when overdose is not considered.

\section{Conclusion}

From this seven-country, 3-year, case-population study of ALF leading to registration on transplantation lists, it appears that the presence of an NSAID within 1 month before the first symptoms of ALFT is rare, and that there is evidence of a relevant difference between the different mainstream NSAIDs for population-time exposure rates. The event rate of ALFT exposed to non-overdose paracetamol was more than 2-fold higher than for all NSAIDs pooled, and higher than most individual NSAIDs.

Acknowledgments The authors wish to thank all the physicians and staff at the transplant centres, all the patients whose acceptance of this study made it possible, and the various people in administrative positions, data protection, ethics and the British R\&D committees.

The corresponding authors had full access to all of the data in the study and take responsibility for the integrity of the data and accuracy of the data analysis, which was conducted independently from the funder.

The manuscript was reviewed by Philip Robinson, $\mathrm{PhD}$, a medical writer employed by the University of Bordeaux, Department of Pharmacology.

Conflicts of interest No specific conflicts of interest are declared with regard to this study, by any of the authors, inasmuch as for a number of the authors who are employees of the University of Bordeaux, the University of Bordeaux received compensation as described below. Authors participating in the committees received compensation from the University of Bordeaux for the time spent on the committees.

Nicholas Moore has received compensation from other manufacturers of NSAIDs (Novartis, Almirall, Reckitt Benckiser, Roche, Pfizer, etc.) for advice or consultation on the gastrointestinal or cardiovascular safety or utilization patterns of OTC NSAIDs, but not on their hepatotoxicity. He received no compensation from Helsinn at any time during the study. All study-related expenses were paid for by the University of Bordeaux from contractual financing by Helsinn. Nicholas Moore has been working on the risks of NSAIDs, including OTC doses, for many years and has worked with Boots, Reckitt, Roche, Pfizer, Merck, Novartis, Helsinn, Aventis, Sanofi, Almirall and others on studies of NSAID utilization and risks, including cohort studies, case-population studies, clinical trials, meta-analyses and expert reports or testimonies before courts of law or regulatory authorities such as the EMA, US FDA and national authorities over the last 20 years.

Estela Monteiro has been paid as a national coordinator among selected centres in Portugal.

Corinne de Vries has received financial support for travel to study meetings.

Susana Perez-Gutthann is a salaried employee of RTI Health Solutions, a division of Research Triangle Institute (RTI) Interna- tional. Numerous pharmaceutical companies contract work with RTI, through grants and consultation contracts. In her department, this work includes studies, pre-research activities (study design, protocol development, feasibility evaluations), literature evaluation, and safety regulatory and Risk Management Plan-driven work and general pharmacoepidemiology and risk management. Her compensation comes from RTI in the form of a salary, and she does not receive any compensation beyond this. RTI Health Solutions received unrestricted funding from Helsinn, the manufacturer of nimesulide, to conduct a study on nimesulide, NSAID and gastrointestinal bleeding, of which Susana Perez-Gutthann is the principal investigator. Helsinn has also contracted literature reviews and study evaluations. She has also led work to develop post-approval studies funded by Nicox, a developer of NSAIDs.

Yves Horsmans has received consulting fees from Helsinn, Switzerland.

During the time of this study, our Department of Pharmacology, University of Bordeaux, also had contracts on other matters and other drugs with pharmaceutical companies manufacturing NSAIDs or paracetamol, not pertaining to the subject of the study or the drugs under consideration. Since most drug manufacturers market NSAIDs either as princeps (branded) drugs or as generics, it is difficult to work with any pharmaceutical company without falling into the category above.

None of the authors received any direct compensation for consultation concerning NSAID-related hepatotoxicity during the course of the study.

Financial support This study was funded by Helsinn Healthcare SA (HHC), manufacturers of nimesulide, at the request of the EMA's CHMP, but was conducted independently. The sponsor had no role in the design of the study, which was submitted to and approved by the CHMP, or in the collection, management, analysis or interpretation of the data. Nor did they have any role in the preparation or review of this manuscript. They were given the opportunity to read and comment on this paper before submission, but the content of the paper was entirely under the control and responsibility of the authors. HHC contracted with the University of Bordeaux for the conduct of the study. All contracts with experts or transplant centres were with the University of Bordeaux. HHC had no direct contact with any of the participants in the study.

The report of this study was sent to the regulatory authorities and was presented to the CHMP on 17 May 2011.

Author contributions Nicholas Moore and Dominique Larrey had the original idea for the study several years ago, and proposed it to the sponsor and to the CHMP. Nicholas Moore was the overall study supervisor, intervening when necessary for the smooth operation of the study. He also finalized this article. Dominique Larrey was chairman of the scientific committee and the case adjudication committee, and was the everyday hepatology counsel for the study. George-Philippe Pageaux was the vice-chairman of the case adjudication committee, and contributed enormously to case understanding and adjudication.

Sinem Ezgi Gulmez and Séverine Lignot were the scientific and operational study coordinators, devising the initial document generation under the control of the scientific committee, organizing negotiations with transplant centres and study data retrieval, writing the study reports, drafting the article and verifying all contents. The study coordination team also included Fatima Hamoud and Sophie Micon, who coordinated the scientific and case adjudication committee activities. Régis Lassalle and Jérémy Jove provided data management and statistical analyses. Cécile Droz-Perroteau was overall supervisor of operations. Patrick Blin was the study epidemiological overseer, contributing to study design, operations, analysis 
and understanding. Francesco Salvo contributed to study operations, especially for coordination with Italian centres.

George-Philippe Pageaux, Angelo Gatta, P. Aiden McCormick, Harold J. Metselaar, Estela Monteiro, Douglas Thorburn, William Bernal and Irene Zouboulis-Vafiadis were Chairpersons of their respective national case selection committees and had considerable importance in the acceptance of the study in their countries.

Corinne de Vries, Susana Perez-Gutthann, Miriam Sturkenboom, Jean-Louis Montastruc and Jacques Benichou provided methodological and biostatistical input.

All authors contributed comments to the final version of this paper.

Open Access This article is distributed under the terms of the Creative Commons Attribution Noncommercial License which permits any noncommercial use, distribution, and reproduction in any medium, provided the original author(s) and the source are credited.

\section{References}

1. Reuben A, Koch DG, Lee WM, Acute Liver Failure Study Group. Drug-induced acute liver failure: results of a U.S. multicenter, prospective study. Hepatology. 2010;52(6):2065-76.

2. Keisu M, Andersson TB. Drug-induced liver injury in humans: the case of ximelagatran. Handb Exp Pharmacol. 2010;196: 407-18.

3. Lee WM. Drug-induced hepatotoxicity. $\mathrm{N}$ Engl J Med. 2003;349(5):474-85.

4. Danan G, Trunet P, Bernuau J, Degott C, Babany G, Pessayre D, et al. Pirprofen-induced fulminant hepatitis. Gastroenterology. 1985;89(1):210-3.

5. Bessone F. Non-steroidal anti-inflammatory drugs: what is the actual risk of liver damage? World J Gastroenterol. 2010;16(45): 5651-61.

6. Traversa G, Bianchi C, Da Cas R, Abraha I, Menniti-Ippolito F, Venegoni M. Cohort study of hepatotoxicity associated with nimesulide and other non-steroidal anti-inflammatory drugs. BMJ. 2003;327(7405):18-22.

7. Lee $\mathrm{CH}$, Wang JD, Chen PC. Increased risk of hospitalization for acute hepatitis in patients with previous exposure to NSAIDs. Pharmacoepidemiol Drug Saf. 2010;19(7):708-14.

8. Theophile H, Laporte JR, Moore N, Martin KL, Begaud B. The case-population study design: an analysis of its application in pharmacovigilance. Drug Saf. 2011;34(10):861-8.

9. Gulmez SE, Lignot-Maleyran S, DeVries C, Sturkenboom M, Micon S, Hamoud F, et al. Administrative complexities for a European observational study despite directives harmonising requirements. Pharmacoepidemiol Drug Saf. 2012;21:851-6.

10. O'Grady JG. Acute liver failure. Postgrad Med J. 2005;81(953): $148-54$.

11. O’Grady JG, Alexander GJ, Hayllar KM, Williams R. Early indicators of prognosis in fulminant hepatic failure. Gastroenterology. 1989;97(2):439-45.

12. Bernuau J, Goudeau A, Poynard T, Dubois F, Lesage G, Yvonnet $\mathrm{B}$, et al. Multivariate analysis of prognostic factors in fulminant hepatitis B. Hepatology. 1986;6(4):648-51.

13. Benichou C. Criteria of drug-induced liver disorders: report of an international consensus meeting. J Hepatol. 1990;11(2):272-6.

14. Benichou C, Danan G, Flahault A. Causality assessment of adverse reactions to drugs: II. An original model for validation of drug causality assessment methods: case reports with positive rechallenge. J Clin Epidemiol. 1993;46(11):1331-6.
15. Danan G, Benichou C. Causality assessment of adverse reactions to drugs: I. A novel method based on the conclusions of international consensus meetings: application to drug-induced liver injuries. J Clin Epidemiol. 1993;46(11):1323-30.

16. Danan G, Benichou C, Begaud B, Biour M, Couzigou P, Evreux JC, et al. Criteria of imputation of acute hepatitis to a drug: results of consensus meetings [in French]. Gastroenterol Clin Biol. 1987;11(8-9):581-5.

17. Guidelines for ATC classification and DDD assignment. 4th ed. Oslo: WHO Collaborating Centre for Drug Statistics Methodology; 2001.

18. Fourrier-Reglat A, Cuong HM, Lassalle R, Depont F, Robinson $\mathrm{P}$, Droz-Perroteau C, et al. Concordance between prescriber- and patient-reported previous medical history and NSAID indication in the CADEUS cohort. Pharmacoepidemiol Drug Saf. 2010; 19(5):474-81.

19. Fourrier-Reglat A, Lacoin L, Pariente A, Lassalle R, Robinson P, Droz-Perroteau $\mathrm{C}$, et al. When patients report diseases that prescribers seem unaware of: discordance between patient and physician reporting of risk-related previous history in NSAID users from the CADEUS study. Clin Pharmacol Ther. 2010; 88(5):668-75.

20. Moore N, Pierfitte C, Pehourcq F, Lagnaoui R, Begaud B. Comparison of patient questionnaires, medical records, and plasma assays in assessing exposure to benzodiazepines in elderly subjects. Clin Pharmacol Ther. 2001;69(6):445-50.

21. Depont F, Fourrier A, Merliere Y, Droz C, Amouretti M, Begaud $\mathrm{B}$, et al. Channelling of COX-2 inhibitors to patients at higher gastrointestinal risk but not at lower cardiovascular risk: the Cox2 inhibitors and tNSAIDs description of users (CADEUS) study. Pharmacoepidemiol Drug Saf. 2007;16(8):891-900.

22. Depont F, Fourrier A, Merliere Y, Droz C, Amouretti M, Begaud $\mathrm{B}$, et al. The CADEUS study: methods and logistics. Pharmacoepidemiol Drug Saf. 2007;16(5):571-80.

23. Chalasani N, Bjornsson E. Risk factors for idiosyncratic druginduced liver injury. Gastroenterology. 2010;138(7):2246-59.

24. Maddur H, Chalasani N. Idiosyncratic drug-induced liver injury: a clinical update. Curr Gastroenterol Rep. 2011;13(1):65-71.

25. Aithal GP, Day CP. Nonsteroidal anti-inflammatory drug-induced hepatotoxicity. Clin Liver Dis. 2007;11(3):563-75, vi-vii.

26. Ponsoda X, Bort R, Jover R, Gomez-Lechon MJ, Castell JV. Molecular mechanism of diclofenac hepatotoxicity: association of cell injury with oxidative metabolism and decrease in ATP levels. Toxicol In Vitro. 1995;9(4):439-44.

27. Stirnimann G, Kessebohm K, Lauterburg B. Liver injury caused by drugs: an update. Swiss Med Wkly. 2010;140:w13080.

28. Graham GG, Day RO, Graudins A, Mohamudally A. FDA proposals to limit the hepatotoxicity of paracetamol (acetaminophen): are they reasonable? Inflammopharmacology. 2010;18(2): $47-55$.

29. Guggenheimer J, Moore PA. The therapeutic applications of and risks associated with acetaminophen use: a review and update. J Am Dent Assoc. 2011;142(1):38-44.

30. Craig DG, Bates CM, Davidson JS, Martin KG, Hayes PC, Simpson KJ. Staggered overdose pattern and delay to hospital presentation are associated with adverse outcomes following paracetamol-induced hepatotoxicity. Br J Clin Pharmacol. 2011.

31. Sabate M, Ibanez L, Perez E, Vidal X, Buti M, Xiol X, et al. Paracetamol in therapeutic dosages and acute liver injury: causality assessment in a prospective case series. BMC Gastroenterol. 2011;11:80.

32. Larson AM, Polson J, Fontana RJ, Davern TJ, Lalani E, Hynan LS, et al. Acetaminophen-induced acute liver failure: results of a United States multicenter, prospective study. Hepatology. 2005;42(6):1364-72. 
33. Andrade RJ, Lucena MI, Garcia-Escano MD, Camargo R. Severe idiosyncratic acute hepatic injury caused by paracetamol. J Hepatol. 1998;28(6):1078.

34. Prescott LF. Paracetamol: past, present, and future. Am J Ther. 2000;7(2):143-7.

35. Prescott LF. Therapeutic misadventure with paracetamol: fact or fiction? Am J Ther. 2000;7(2):99-114.

36. Prescott LF. Paracetamol, alcohol and the liver. Br J Clin Pharmacol. 2000;49(4):291-301.
37. Lee WM, Hynan LS, Rossaro L, Fontana RJ, Stravitz RT, Larson $\mathrm{AM}$, et al. Intravenous $\mathrm{N}$-acetylcysteine improves transplant-free survival in early stage non-acetaminophen acute liver failure. Gastroenterology 2009;137(3):856-64, 864.e1.

38. Weise AM, Liu CY, Shields AF. Fatal liver failure in a patient on acetaminophen treated with sunitinib malate and levothyroxine. Ann Pharmacother. 2009;43(4):761-6. 